\title{
Intertwining Practices and Uses of ICT: A Cultural Digital Analysis
}

\author{
Hanen Khanchel ${ }^{1}$ \\ ${ }^{1}$ Institute of Advanced Business Studies, Carthage, Tunisia \\ Correspondence: Hanen Khanchel, Institute of Advanced Business Studies, Carthage, Tunisia. E-mail: \\ Hanen.Khanchel@gmail.com
}

Received: May 15, 2020 Accepted: May 28, 2020 Online Published: June 8, 2020

doi:10.5430/jbar.v9n1p21 URL: https://doi.org/10.5430/jbar.v9n1p21

\begin{abstract}
National culture is a central principle in understanding employees' behavior. When communication practices are incompatible with the values of employees, they are likely to feel dissatisfied, distracted, and uncommitted. As a result, they may have less ability or desire to perform. Instead, consistency between practices of communication and the characteristics of the national culture leads to better performance. This study highlights some elements of cultural analysis by identifying the behavior of groups by combining their communication practices, their ICT equipment and the uses they make of it. We identify five very distinct profiles ranging from "univores" to "multi-omnivores", whose membership factors we test. It seems that the more diverse the use of ICT, the more the individual has a diversified consumption of the time budget. More finely, the "culture of digital networks" positively explains the degree of technophilia. The difficult start of digital communication models can be explained by the generally limited profile of "multi-omnivores" and the geographic location.
\end{abstract}

Keywords: practice, communication, ICT, working time, culture

\section{Introduction}

Practices of communication have been the subject of numerous works in quantitative sociology since the founding works of Bourdieu (1979). The latter addresses this theme from the angle of cultural legitimacy and social distinction. An individual of high social status is supposed to be distinguished by a pronounced taste for the learned arts and high practices such as visiting museums, as well as a disregard for leisure or entertainment described as "popular". Following his work, a whole literature has emerged, often opposing Bourdieu's conclusions, in the form of empirical studies highlighting the eclecticism of communication practices as a distinguishing factor and social norm of good taste. This evolution towards a cultural eclecticism would be due to major social changes like the lengthening and the increase of the level of education, the transformation of the social networks of the individuals (Khanchel, 2019a), the influence of popular culture on the "high" arts accompanying the entry into postmodernity, a competition of legitimacy between popular culture and elitist culture. The invasion of the audio-visual and, now, of the Internet in the field of the culture and the practices of leisures, would also play a role, supporting the access of the elite to more popular forms of communication and conversely, the access of individuals of lower social status to elitist culture (Donnat, 1994; Lahire, 2004). However, the works from those of Hofstede invariably analyze the same national cultural backgrounds (Khanchel and Ben Kahla, 2018a). Most often the American, French, British, Canadian, Japanese and a lesser Chinese measure (Harrison and Mckinnon, 1999; Joannides, 2011) are compared. Consequently, few are interested in developing countries (Joannides, 2011). In addition, it has no studies that examine the differences in practices of communication in Tunisia. According to Hofstede's results, the cultural variables of the Arab countries are relatively marked. It is certainly to be noted that Hofstede in his model of analysis of cultural differences was not interested in Tunisia. We will however rely on the scores assigned by Hofstede to these Arab countries with regard to the four cultural dimensions, namely hierarchical distance, individualism, control of uncertainty and femininity / masunility, given that Tunisia does part of the Arab countries. These scores will serve as a basis for explaining the cultural specificities of the Tunisian context.

The objective of this article is to measure the intrusion of ICT into the daily lives of individuals and to understand the relationships between their massive diffusion and communication practices. To what extent are ICT users also consumers of time budgets? Do the profiles correspond to a targeted audience or do they broaden to new social categories through the elimination of geographic constraints? Could ICT be a vector for diversifying the practices of communication? Are there not behavioral inertias confining the models to profiles of targeted time budget consumers? 
Conversely, what are the factors likely to increase access to this equipment?

The article is composed as follows. The first part consists in identifying the factors likely to explain the practices of communication and the uses studied through a review of the literature, in particular in quantitative sociology and cultural analysis of digital inequalities. A second part describes our methodology. In addition to the originality of our method of data analysis consisting in crossing dimensions, we integrated, in a new way compared to the empirical studies relating to the communicative practices, variables aiming to estimate the influence of the socio-cultural variables. A third part presents the empirical results relating to the categorization of time budget consumer profiles and the determinants of belonging to these profiles. In conclusion, we offer some empirical evidence to assess this demand. The proposed approach aims to identify and compare profiles of individuals by relating practices of communication with ICT equipment to test the determinants of individuals' belonging to each of the profiles identified. A first originality of this study is not to confine oneself to an analysis on a specific genre or a precise use, but to take into account a multiplicity of practices in both cases. Therefore, it is not a question of studying the influence of ICT on the diversification of communication practices but, rather, of understanding to what extent the types of practices intertwine and, from the findings, highlight the factors that may explain the difficulties encountered by Tunisians. This orientation of our research seems all the more justified and the analysis of the influence of the use of ICT on practices of communication is all the less.

\section{Literature Review}

Identified by various authors, including Peterson (1992) and DiMaggio (1987), this eclecticism is expressed both in terms of diversified tastes and of cumulative practices. A number of works in quantitative sociology emphasize that individuals are distinguished socially, not by the very nature of the services they access, but by the diversification (omnivality) or not (univality) of their communication practices. Indeed, with the notion of omnivality, various reasons are put forward by the literature to explain the propensity of individuals to diversify their communication practices (Coulangeon, 2004).

A first approach presupposes a predisposition of individuals to eclecticism, itself inherited from the environment of origin. The environment of origin would also explain the universality, which would thus be closely linked to cultural capital and level of education (Bryson, 1997). For Peterson (1992), in addition to a univority linked to a disadvantaged social status, there is also a "high status univorism" characterizing individuals voluntarily limiting their communication practices given their religious beliefs, a sectarian attitude or, sometimes, a form of intellectual snobbery. This social determinism would then explain different capacities for absorption and interpretation of novelty. According to Coulangeon (2004), communication is social interaction that requires at least two people who share a common set of signs and semiotic rules.

A second approach considers the degree of diversification between communication practices as a consequence of the composition of social relationships, of the social environment. Depending on the size of his social network and the multiplicity of his interactions, the individual is pushed to acquire knowledge and to multiply his leisure practices, in particular communication, to maintain his relationships (DiMaggio, 1987; Erickson, 1996; Relish, 1997; Lahire, 2004). Similarly, according to a logic of "situated rationality" (Kirman, 1992), the individual whose social environment develops a strong propensity to diversify his practices will have an interest in adopting a similar behavior. In communication omnivity in order to mark membership in the group or to save on costs linked to purely individual decision-making. Furthermore, the distance from political power is measured from the value systems of those who have the least hierarchical authority in society (Arcand, 2006). In countries where the index of this dimension is strong, power is a basic fact (Bollinger \& Hofstede, 1987). Hence, the communication omnivity is once again positively linked to social status.

Other sociological factors also count, such as generational effects and household composition. The younger the individual, the more omnivorous it is due to less time constraints, more developed social interactions and, possibly, more open, less shaped tastes (Coulangeon, 2003; Fisher and Preece, 2003; van Eijck, 2001 ; Guy 2000). Likewise, living as a couple, with children, can influence omnivity either by limiting social interactions, or by weighing on the free time available outside of family-oriented activities (Degenne et al., 2002).

Finally, another type of explanation for omnivality is based on the assumption of substantive rationality in human behavior. The diversification of communication practices could be explained according to a logic of rational allocation of time aimed at optimizing the total utility obtained through these activities. The extent and diversification of practices outside of work are subject to a time constraint, forcing the individual to optimize his choices in terms of leisure time management. Becker (1965) integrates this arbitration by considering the utility withdrawn by consumers, not from the goods and services they consume, but from non-professional activities linked 
to the combination of goods and services with time. The individual is therefore subject to two constraints, in this case his income and his time available, which it can reduce by investing in human capital (Becker, 1964) to increase the return on time from non-professional activity and, therefore, the diversity of its activities. The higher socio-professional categories would therefore be more "productive" and therefore more eclectic (Degenne and al., 2002; Coulangeon, Menger, \& Roharik, 2002).

The classic demographic variables, in particular professional activity, income and age, but also the variables linked to the social environment make it possible to distinguish individual profiles. Note, however, that the "digitalization" of communication practices also contributes to extending the time devoted to their consumption. This consumption of time budget observed is itself less restrictive than the communication outings that, for their part, fix the individual in a precise workplace. In this context, the use of ICT would encourage the diversification of these practices (Granjon \& Combes, 2007; Donnat, 2007).

ICT can alleviate time constraints and encourage the renewal of modes of communication via digital networks and the multiplication of social interactions (Khanchel, 2019b). However, the individual must have access to these digital devises and know how to use them effectively to benefit from online services. Therefore, user profiles are distinguished not only by access to ICT but also by the type of use and its intensity. However, it is difficult to summarize the question of the "digital divide" to the deterministic observation according to which inequalities in the equipment and use of ICTs are caused by social, geographic or generational inequalities and therefore justify adapted "catch-up" economic policies. If equipment plays an important role, this is by no means a sufficient condition. Still, individuals need to want to use ICTs and use the services that pass through digital networks (Le Guel et al., 2005). Suffice it to say that the so-called "digital divide" between women and men ends with texting or blogging (Khanchel and al, 2016).

The notions of individual trajectories and unsuitability of the offer appear to us more relevant than those of "fractures" and "digital delays" (Rallet \& Rochelandet, 2007; Khanchel and al, 2016). Part of the consumers thus have a clear preference for the "ready-to-use", the ready-to-use, based on an ergonomic service, while, according to a logic of "do-it-by-yourself", another part, more technophile, assumes the costs of learning and using the ICT necessary for the consumption of online services. There is therefore no universal model for appropriating ICTs, but differentiated trajectories, shaped as much by history, culture and individual needs, as by the ability of providers to respond adequately to or create existing needs.

The variables underlying these individual trajectories are therefore essential to identify. The literature on inequalities in the use of ICT has highlighted different factors of inequality: generational effects, computer skills and those linked to internet use, socio-professional category, income level, geographic location, the influence of the social environment and relatives (DiMaggio et al., 2004; Chen \& Wellman, 2005; Montagnier, Muller, \& Vickery, 2002; Hargittai, 2002; Sciadas, 2002; Johnston, 2001). For example, the density of an individual's social interactions conditions the intensity of use, but also the diversity of communication tools used to maintain their social network. These variables explain not only the profiles of users (or non-users) but, the relationships between the forms of use of ICT and the communication modes can be viewed in both directions. ICT can modify communication practices by potentially alleviating various constraints regarding the adoption of these new practices. These constraints are notably geographic; temporal; informational; and relational (new forms of inter-individual communication and coordination).

Conversely, communication practices are likely to influence the forms of use of ICT. The diversification of their modes of communication would lead individuals to develop an aptitude or a propensity to discover and diversify their practices in other fields and, in particular, the use of ICT. Likewise, promoting and maintaining eclecticism makes it possible to multiply or strengthen existing social relationships and integrate different social networks (Khanchel, 2019b). Cultural capital can facilitate its interactions, or even multiply its relationships in participatory networks. The anonymity and limited knowledge of the other participants make them suitable places for the enhancement of cultural capital. Cultural omnivality would allow individuals to maintain repeated relationships, even if they are only virtual. It would be a way of overcoming the incompleteness of interactions arising from imperfect information about partners. The diversity of communication practices would thus be an important matching and interaction tool allowing increasing or maintaining its social capital.

In the end, the circularity characterizes the relationships between communication practices and the use of ICT, making an analysis that would only deal with the influence of ICT on consumption patterns of the time budget constraints. Our research strategy differs from this perspective by focusing on the hypothesis and explanation of the intertwining of the two types of individual behavior. ICT can also influence the value that individuals attribute to 
communication practices and on this basis, their communication practices. Income level, social network composition or generational effects can help diversify the uses of ICT. In turn, this diversification can fuel omnivial communication. Thus, reading blogs or building new social links on the internet facilitate the discovery of new communication categories that can lead individuals to diversify their practices (Granjon \& Combes, 2007). In this respect, the time devoted to ICT is doubly destructive compared to communication practice.

\section{Method}

Our objective is to build and explain profiles by crossing the communication practices of individuals, their ICT equipment and the use they make of it in the different worlds of life. Thus, it is a question of identifying the dominant characteristics for each individual and for each of the variables considered.

Data analysis takes place in two stages. First, a typology of behaviors is developed for each of the dimensions considered. In a second step, we cross these different typologies to build typical profiles of individuals. In both cases, we use the same classification methods.

\subsection{Data and Variables Used}

To construct the cross profiles and estimate the probability of belonging to each of these profiles, we used data from the World Values Survey.

Regarding our data analysis, individuals are classified according to three main dimensions: ICT equipment, use of ICT and communication practices. In some cases, indices have been developed by selecting variables from the World Values Survey.

\subsection{Classification and Identification Method for Cross Profiles}

Two classification methods are successively used to identify typical profiles of individuals: an ascending hierarchical classification $(\mathrm{CAH})$, from which were selected standard groups of individuals intended to initialize a classification according to mobile centers (CCM).

We operated, in a first step, a classification of individuals from a CAH. This algorithm consists in first grouping together the two closest individuals in the same class. Then, the two closest classes are grouped together, using the Ward distance. The concatenation operation is repeated until a single class is obtained. From this algorithm are developed the hierarchical tree and the histogram of the level indices, which highlight, when one passes from a configuration of $n$ classes to $n-1$ classes, the gain of inertia class and therefore a degree of loss of homogeneity of the partition. The higher this loss, the more we tend to consider that the configuration with $\mathrm{n}$ classes is statistically a "good" configuration. In the case of the hierarchical tree, the length of the steps is proportional to the loss of inter-class inertia caused by grouping of classes. In the histogram of the level indices, this loss can be visualized by comparing the successive importance of inter-class inertia of the partitions. A high loss of inter-class inertia means that the two classes that were grouped were quite distant from each other. A "good" partition can be considered as a partition which precedes a significant loss of inertia between classes. It is this criterion, commonly accepted for choosing the number of $\mathrm{CAH}$ classes, that we have used in this article.

However, the limit of the $\mathrm{CAH}$ is that it does not necessarily lead to the lowest intra-group inertia for the number of groups selected. The CCM does not suffer from this limitation. It consists in fixing a priori a number of reference individuals equal to the number of desired groups then in calculating the distance between each individual in the sample and these reference individuals. For each individual, we identify the closest reference individual. A group of closest individuals is thus created for each reference individual. Once this first series of groups is obtained, we calculate their center of gravity, which we assimilate to new reference individuals, and we iterate the method until the intra-group inertia does not change anymore. However, the CCM also has a defect: the initial reference individuals are chosen arbitrarily. The results obtained are therefore sensitive to the choice of these initial points. To overcome this difficulty, we used, in our second step, the centers of gravity of the groups resulting from the first step (the results of the $\mathrm{CAH}$ ) as initial reference individuals of the CCM.

Our method classification (a CAH followed by a CCM) was applied in two stages: first to highlight the profiles of individuals on each of the three dimensions identified (communication practices, ICT equipment and their uses) and, secondly, to obtain cross profiles of individuals. To do this, we have classified, in this second step, individuals simultaneously on the three dimensions based on the variables of belonging to the profiles obtained in the first step.

\section{Results}

We have obtained five cross profiles and six universes below that it is possible to characterize from the detailed results according to the following diagrams: 

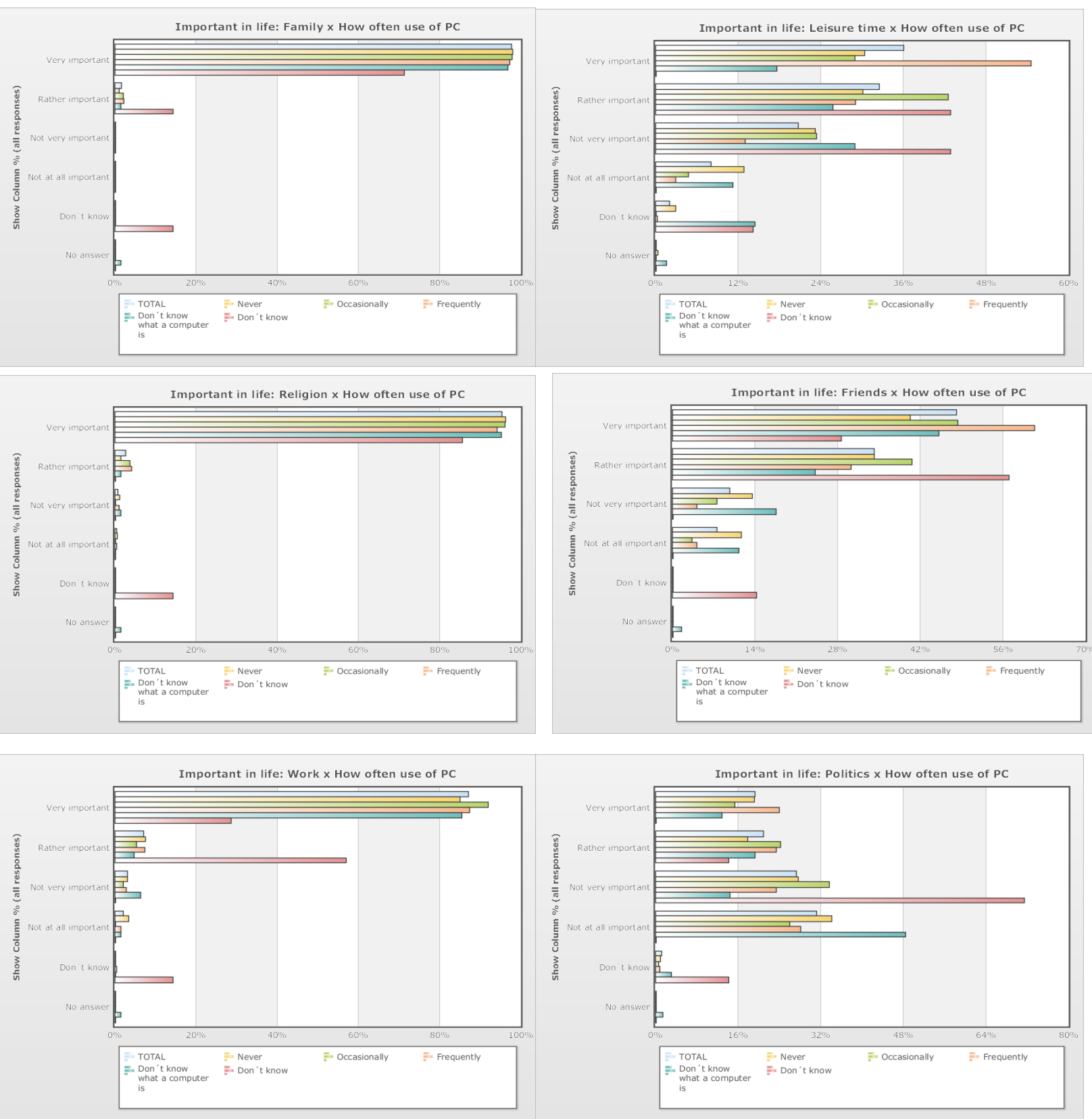

Source: Exploitation of the data from the World Values Survey (2014)

Two polar cases stand out:

- Profile 1 (the "univores"): their dominant use of ICT is in the family universe. This profile is situated between the world of exclusion and that of the average Tunisian in the six universes identified by the World Values Survey.

- Profile 5 ("multi-omnivores"): unlike "univores", this profile of individuals combines heterogeneous communication practices and a diversified use of ICT.

Between these two polar cases, three intermediate profiles are distinguished:

- Profile 2: this profile is associated with "professional" communication practices, but uses ICT only to communicate via a mobile phone and sometimes by SMS. It is also distinguished from "univores" by a fixed computer equipment, although it has no particular use; 
- Profile 3: this profile is similar to profile 2 through its communication practices. However, he is more of an ICT user. It consumes, admittedly marginally;

- Profile 4: despite equipment similar to Profile 3, this profile stands out clearly through its use of ICT (technophiles approaching the "multi-omnivore" profile) but, also, through its communication practices oriented towards the screen.

The objective is to determine to which cross-section an individual belongs based on their socio-demographic characteristics. For this, we study, using a multinomial logit model, the propositions established from the literature.

Outraged demographic variables, we also used variables relating to location, as well as to social interactions. For explanatory variables such as the degree of sociability of the individual, scores were developed by selecting variables from the World Values Survey.

Gender is a variable whose effects are undetermined (Khanchel and Ben Kahla, 2018b). Communication practices and use of ICT differ from one sex to another. But it is difficult to infer a priori the impact on the diversification of practices. On the other hand, marital status and, in particular, the fact that the individual is single or living as a couple, with or without children, can have an impact on their available time and therefore limit the diversification of their occupations.

The generational effects are evaluated by age: the younger the individual, the more he is supposed to be able to adapt to newness and therefore the more this variable will have a negative effect on the probability of belonging to profiles tending towards omnivality, in particular through a high and diversified use of ICT.

The level of education can account for human capital. Based on Becker's analysis (1965), this variable is supposed to have a positive effect on the probability of belonging to profiles tending towards "multi-omnivality".

Social status is characterized by both profession and socio-professional category (PCS) and income. These two variables have a presumed positive effect on belonging to an "omnivorous" profile in terms of both communication practices and the use of ICT. They are notably supposed to allow the multiplication of practices financially. Likewise, the more individuals have a high social status, the more they need to maintain their social network by having communicational practices and uses of diversified ICTs.

The location is assessed by the size of the municipality. It makes it possible both to account for the proximity of the premises and the proximity and age of telecommunication infrastructures which earlier favored the adoption of ICT by individuals. We also tested whether living in an area covered by the internet or not could have an impact on the degree of diversification of communication practices.

Social entourage, finally, is supposed to positively influence membership of profiles based on a diversification of communication practices. To conduct such an analysis, however, it is necessary to distinguish the different levels of social environment likely to have varied effects, since practices diverge and become individualized at the different stages of the individual's life. Data from the World Values Survey allow us to distinguish the influence of family and friends. In addition, we tested another social interaction variable available in the survey, namely participation in an association. However, no other variable in the survey allowed us to further study these influences.

Table 1 shows the explanatory variables used as well as the expected effects on the probability of belonging to the "multi-omnivore" profile.

Finally, it should be noted that the dependent variable (profile) is not as such an ordered variable, because if profiles 1 ("univores") and 5 ("multi-omnivores") are hierarchical as regards the intensity and diversity of practices, intermediate profiles are more difficult according to objective criteria. In general, these profiles result from an analysis of data, therefore from a combination of different variables. This explains why we did not opt for an ordered logit model. 
Table 1. Variables and expected effects

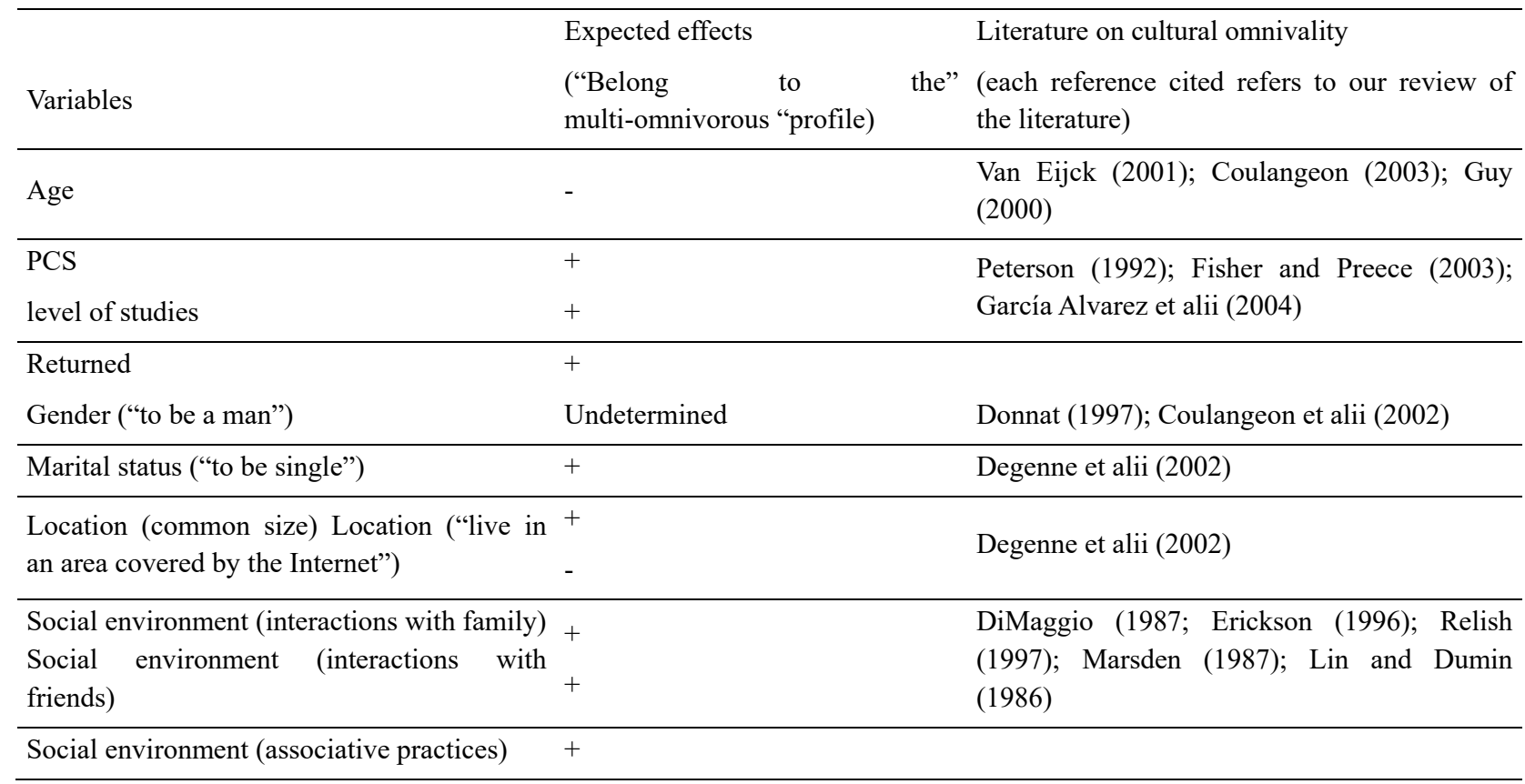

\section{Discussion}

First, socio-demographic variables have contrasting effects. A part from marital status, the determinants linked to age, gender, PCS, level of education and income explain the differences in profiles relatively well, in accordance with the results usually highlighted for communication and digital practices. In particular, age has a negative and significant effect on the probability of belonging to different profiles compared to that of univores. The calculation of elasticities as a function of age specifies this result. Table 2 below shows that, depending on the profiles, the proportional variation in age has a different impact on the proportional variation in belonging to a profile.

Table 2. Impact of the explanatory variables on the probability of belonging to each profile compared to profile 1 ("univores") (multinomial logit model)

\begin{tabular}{|c|c|c|c|c|}
\hline & Profile 2 & Profile 3 & Profile 4 & Profile 5 \\
\hline \multirow[b]{2}{*}{ Description } & ICT use & Small use of ICT & Average use of ICT & \\
\hline & $\begin{array}{l}+{ }_{\text {communication }} \text { classic } \\
\text { practices }\end{array}$ & $\begin{array}{l}+{ }_{\text {communication }} \text { classic } \\
\text { practices }\end{array}$ & $\begin{array}{l}+\quad \text { classic } \\
\text { communication } \\
\text { practices }\end{array}$ & Multi-omnivorous \\
\hline Age & $(-) * * *$ & $(-) * * *$ & $(-) * * *$ & $(-) * * *$ \\
\hline Gender (“man”) & Ns & ns & $(+) * * *$ & $(+) * * *$ \\
\hline Marital status (“couple") & Ns & $(-) * *$ & ns & ns \\
\hline level of studies & $(+) * * *$ & $(+) * * *$ & $(+) * * *$ & $(+) * * *$ \\
\hline$\overline{\text { PCS1 (inactive) }}$ & $(+) * *$ & ns & ns & ns \\
\hline $\begin{array}{l}\text { PCS3 (craftsmen, } \\
\text { traders, entrepreneurs) }\end{array}$ & Ns & ns & ns & ns \\
\hline \multicolumn{5}{|l|}{$\begin{array}{ll}\text { PCS4 } & \text { (executives, } \\
\text { professions }\end{array}$} \\
\hline liberal, professions & ns & $(+) * *$ & $(+) * * *$ & $(+) * * *$ \\
\hline
\end{tabular}




\begin{tabular}{|c|c|c|c|c|}
\hline \multicolumn{5}{|l|}{ higher intellectuals) } \\
\hline Returned & $(+) * * *$ & $(+) * * *$ & $(+) * * *$ & $(+) * * *$ \\
\hline Municipality size & $(+) * * *$ & $(+) * * *$ & $(+) * * *$ & $(+) * * *$ \\
\hline Internet coverage area & ns & ns & ns & ns \\
\hline $\begin{array}{l}\text { Social } \\
\text { (family) }\end{array}$ & ns & ns & $(-) * * *$ & ns \\
\hline Social circle (friends) & $(+) * * *$ & $(+) * * *$ & $(+) * * *$ & $(+) * * *$ \\
\hline Associative practices & ns & $(+) * * *$ & $(+) * *$ & $(+) * * *$ \\
\hline
\end{tabular}

The mention ns indicates that the variable is not significant.

Age is all the more important as the class corresponds to more diversified practices. There would therefore be a generational effect both in omnivial communication and in the diversified use of ICT. This observation is verified for gender only for the two most diverse profiles, particularly in terms of the use of ICT. Men are therefore more likely to belong to profiles 4 and 5 .

Then concerning the variables related to social status, in this case the level of education and income have a positive, significant and increasing effect from one class to another. Conversely, if the PCS have an effect, it is not always significant. Thus, the discretization of the PCS shows that being inactive explains class 2 relatively well compared to being univore: retired people (widely represented in the group of inactive) having more time can thus devote more time to leisure activities, but without having a diversified use of ICT (profile 2). Senior managers have a much higher probability of belonging to profiles 4 and 5 (the most technophile and diversified in terms of communication practices than other PCS).

A more striking result is that "social status" is not the only distinguishing factor in profiles. Belonging to them is also explained by interactions with friends ("social capital"). Associative practices clearly explain the fact that they belong to the three most technophile and diverse profiles in their communication practices. On the contrary, interestingly and with regard to profile 4, the family seems to play a rather negative role in the adoption and dissemination of uses both in the field of ICT and communication practices. The importance of social interactions between friends confirms the interest that individuals have in exploiting this type of influence. Therefore, the results show that the size of the agglomeration has a positive, significant and increasing effect with profiles. Conversely, living in low-cost housing with familly and friends has no effect on the probability of belonging to any profile.

However, our study reveals the importance given to family values, quality of life and human relationships, as confirmed by Lassoued (2008). At the same time, Tunisian attaches importance to work (Séror and Rejeb 2006). For Ben Fadhel (1992) this reflects a balance between male and female values according to the cultural analyzes of Hofstede (1991). Hence, practices of communication can introduce changes in the daily life of couples and families and strengthen married life and intergenerational relationships (Le Douarin, 2014).

Finally, our results highlight the importance given to respect religion. It is characterized by the prohibition of websites that do not respect the religious values of the country. Furthermore, the study distinguishes religion from other practices like politics or arts. They are also easily and simply applied across societies, no matter how exotic or different the societies are. However, the problem with substantial understanding is that they tend to be too narrow. Individuals' emphasis on belief in the supernatural excludes other religions that do not recognize higher, spiritual being, while also suggesting that religion is primarily about systems of beliefs. Hence, communication involves practices that confer knowledge and experience, give advice and commands, and ask questions. These practices may take many forms depending on the abilities and resources of the individual communicators. Together, content and form make messages that are sent towards a destination. The destination can be oneself, another person, or another entity. Hence, actual practices of communication are often more significant for understanding the emotive, ritual, or habitual dimensions (Zayzafoon, 2005).

\section{Conclusion}

Our results are in line with those obtained by other researchers (Eijck, 2001; Coulangeon, 2003; Guy, 2000; Peterson, 1992, Fisher and Preece, 2003; García Alvarez et alii 2004; Donnat, 1997; Coulangeon et alii 2002; Degenne and alii 
2002; DiMaggio, 1987; Erickson, 1996; Relish, 1997; Lahire, 2004; Marsden 1987; Lin and Dumin 1986). Therefore, we propose an original approach at two levels: first, by developing a method of data analysis taking into account a large number of variables relating to equipment, uses and communication practices and, second, by integrating socio-cultural variables in our analysis aimed at explaining belonging to each of the identified profiles. Although, the consistency between practices of communication and the characteristics of the national culture leads to better performance (Newman and Nollen, 1996).

As for the intensity and diversity of use of ICT, we have seen that inequalities are reflected, at a first level, in terms of access to equipment and services and, at a second level, in terms of use of these facilities and services ("second degree fracture", Hargittai, 2002; DiMaggio et al., 2004). Of course, both of these inequalities can be independent: users are not necessarily equipped, but can benefit from the equipment of others (at work, friends and familly). However, in our analysis, it is important to consider these dimensions when communication practices become supports for individual consumption.

\section{References}

Abbe-Decarroux, F., \& Grin, F. (1992). Risk, Risk Aversion and the Demand for Performing Arts", in Towse R. and Khakee A. (eds), Cultural Economics (pp. 125-140). Springer-Verlag, Berlin. https://doi.org/10.1007/978-3-642-77328-0_14

Arcand, G. (2006), Étude du rôle de la culture nationale dans la relation entre les pratiques de GRH et la performance organisationnelle: le cas des banques de vingt deux pays d'Amérique du Nord, d'Europe et d'Asie, Thèse de doctorat, Université Paul-Verlaine, $305 \mathrm{p}$

Bahuaud, M. (2011). Corinne Destal and Agnès Pecolo, The generational approach to communication: placing the public at the heart of the process. Communication and organization. Retrieved from http://journals.openedition.org/communicationorganisation/3508

Baumol, W. J., \& Bowen, W. G. (1966). Performing Arts: The Economic Dilemma. The Twentieth Century Fund, New York.

Beck, J. (2007). The Sales Effect of Word of Mouth: A Model for Creative Goods and Estimates for Novels. Journal of Cultural Economics, 31(1), 5-23. https://doi.org/10.1007/s10824-006-9029-0

Becker, G. S. (1964). Human Capital: A Theoretical and Empirical Analysis, with Special Reference to Education. NBER - Columbia University Press, New York.

Becker, G. S. (1965). A Theory of the Allocation of Time. The Economic Journal, 75(299), 493-517. https://doi.org/10.2307/2228949

Bollinger and Hofstede. (1987). Les differences culturelles dans le management : comment chaque pays gere-t-il ses hommes? Editions d'Organisation.

Bourdieu, P. (1979). The distinction. Social Criticism of Judgment, Ed. of Midnight, Paris.

Bryson, B. (1997). What about the Univores? Musical Dislikes and Group-based Identity Construction among Americans with Low Levels of Education. Poetics, 25(2-3), 141-156. https://doi.org/10.1016/S0304-422X(97)00008-9

Chen, W., \& Wellman, B. (2005). Charting Digital Divides: Comparing Socioeconomic, Gender, Life Stage, and Rural-Urban Internet Access and Use in Five Countries. In Dutton, W., Kahin, B., O'Callaghan R. and Wyckoff A. (eds.), Transforming Enterprise (pp. 467-497). MIT Press, Cambridge.

Coulangeon, P. (2003). The social stratification of musical tastes. The model of cultural legitimacy in question. Revue française de sociologie, 44(1), 3-33.

Coulangeon, P. (2004). Social classes, communication practices and lifestyles - Is the model of distinction (really) obsolete?. Sociology and Society, 36(1), 59-84. https://doi.org/10.7202/009582ar

Coulangeon, P., Menger, P. M., \& Roharik, I. (2002). Leisure time for the working population: a reflection of social stratification. Économie et Statistique, 352-353, 39-55. https://doi.org/10.3406/estat.2002.7392

De Vany, A. S., \& Walls, W. D. (1996). Bose-Einstein Dynamics and Adaptive Contracting in the Motion Picture Industry. The Economic Journal, 106(439), 1493-1514. https://doi.org/10.2307/2235197

Degenne, A., Lebeaux, M. O., \& Marry, C. (2002). The uses of time: cumulative activities and rhythms of life. Economics and Statistics, 352-353, 81-99. https://doi.org/10.3406/estat.2002.7394 
DiMaggio, P. (1987). Classification in Arts. American Sociological Review, 52(4), 440-455. https://doi.org/10.2307/2095290

DiMaggio, P., Hargittai, E., Celeste, C., \& Shafer, S. (2004). Digital Inequality: From Unequal Access to Differentiated Use. In Neckerman K. (ed.), Social Inequality, Russell Sage Foundation (pp. 355-400). New York.

Donnat, O. (1994). French people face culture. From exclusion to eclecticism, La Découverte, Paris.

Donnat, O. (1997). Survey on French communication practices. Department of Studies and Foresight / Ministry of Culture, La Documentation française, Paris.

Donnat, O. (2004). The cultural universes of the French. Sociology and Society, 36(1), 87-103.

Donnat, O. (2007). Communication practices and uses of the Internet. Culture Études, 2007-3. https://doi.org/10.3917/cule.073.0001

Erickson, B. H. (1996). Culture, Class, and Connections. American Journal of Sociology, 102(1), 217-251. https://doi.org/10.1086/230912

Favaro, D., \& Frateschi, C. (2007). A Discrete Choice Model of Consumption of Cultural Goods: the Case of Music. Journal of Cultural Economics, 31(3), 205-234. https://doi.org/10.1007/s10824-007-9043-x

Fisher, T. C. G., \& Preece, S. B. (2003). Evolution, Extinction, or Status Quo? Canadian Performing Arts Audiences in the 1990s. Poetics, 31(2), 69-86. https://doi.org/10.1016/S0304-422X(03)00004-4

García Alvarez, E., Katz-Gerro, T., \& López Sintas, J. (2007). Deconstructing Cultural Omnivorousness 1982-2002: Heterology in Americans' Musical Preferences. Social Forces, 86(2), 417-443. https://doi.org/10.1093/sf/86.2.417

Glaeser, E. L., Laibson, D., \& Sacerdote, B. (2002). An Economic Approach To Social Capital. Economic Journal, 112(483), 437-458. https://doi.org/10.1111/1468-0297.00078

Granjon, F., \& Combes, C. (2007). The numerimorphosis of music consumption practices. The case of young amateurs . Réseaux, 25(145-146), 291-334.

Guy, J. M. (2000). The cinematographic culture of the French, DEPS Ministry of Culture. La Documentation Française, Paris.

Hargittai, E. (2002). Second-Order Digital Divide: Differences in People's Online Skills. First Monday, 7, 4. https://doi.org/10.5210/fm.v7i4.942

Hennig-Thurau, T., Henning, V., \& Sattler, H. (2007). Consumer File Sharing of Motion Pictures. Journal of Marketing, 71(4), 1-18. https://doi.org/10.1509/jmkg.71.4.1

Hofstede, G. (1991). Cultures and Organizations, Software of the Mind: Intercultural Cooperation and its Importance for Survival. McGraw-Hill.

Johnston, D. J. (2001). Reducing the International Digital Divide. Federal Reserve Bank of Kansas City Proceedings, 193-199.

Khanchel, H., \& Kahla, K. B. (2018a). Intercultural Management between Tunisia and Europe. Journal of Business Administration Research, 7, 40. https://doi.org/10.5430/jbar.v7n2p40

Khanchel, H., \& Kahla, K. B. (2018b). Gender-Role Stereotypes: Perception of Tunisian Leaders. Business and Management Research. https://doi.org/10.5430/bmr.v7n4p22

Khanchel, H., (2019a). Digital Transformation: How to organize the Digital function within the Tunisian Company?. Review of General Management, 29(2).

Khanchel, H. (2019b). Assessing the Community Manager's Performance in Tunisia. International Journal of Current Science and Multidisciplinary Research, No-163

Khanchel, H., Lakhoua, M. A., \& Kahla, K. B. (2016). Key factors of successful e-CRM for optimization of working in front office. Asian Journal of Management and Research, 6(3), 2016.

Kirman, A. P. (1992). What or Whom does the Representative Individual Represent?. Journal of Economic Perspectives, 6(2), 117-136. https://doi.org/10.1257/jep.6.2.117

Kurabayashi, Y., \& Ito, T. (1992). Socio-economic Characteristics of Audiences for Western Classical Music in Japan. 
In Towse R. and Khakee A. (eds), Cultural Economics, Springer-Verlag (pp. 275-287). Berlin. https://doi.org/10.1007/978-3-642-77328-0_27

Lahire, B. (2004). The culture of individuals. Communication dissonance and self-distinction, La Découverte, Paris.

Lassoued, K. (2008). the cultural adaptation of management control, Case of Tunisia, Accounting, control and auditing between change and stability, HAL, France.

Le Douarin Laurence. (2014). Uses of new technologies in families. Social information, 2014/1 (181), 62-71. https://doi.org/10.3917/inso.181.0062

Le Guel, F., Pénard, T., \& Suire, R. (2005). Adoption and commercial use of the internet: an econometric study on Breton data. Économie et Prévision, 1(167), 67-84. https://doi.org/10.3406/ecop.2005.7399

Lévy-Garboua, L., \& Montmarquette, C. (1996). A Microeconometric Study of Theater Demand. Journal of Cultural Economics, 20(1), 25-50. https://doi.org/10.1007/BF00148269

Lin, N., \& Dumin, M. (1986). Access to Occupations through Social Ties. Social Networks, 8(4), 365-385. https://doi.org/10.1016/0378-8733(86)90003-1

Marsden, P. V. (1987). Core Discussion Networks of Americans. American Sociological Review, 52(1), 122-131. https://doi.org/10.2307/2095397

Montagnier, P., Muller, E., \& Vickery G. (2002). The Digital Divide: Diffusion and Use of ICTs. OECD Paper. Retrieved from http://www.oecd.org

Moul, C. C. (2007). Measuring Word of Mouth's Impact on Theatrical Movie Admissions. Journal of Economics \& Management Strategy, 16(4), 859-892. https://doi.org/10.1111/j.1530-9134.2007.00160.x

Newman, K., \& Nollen, S. (1996). Culture and Congruence: The Fit Between Management Practices and National Culture. J Int Bus Stud, 27, 753-779. https://doi.org/10.1057/palgrave.jibs.8490152

Pénard, T., \& Poussing, N. (2006). Internet use and investment in social capital. Louvain Economic Research, 72(4), 413-446. https://doi.org/10.3917/rel.724.0413

Peterson, R. A. (1992). Understanding Audience Segmentation: From Elite and Mass to Omnivore and Univore. Poetics, 21(4), 243-258. https://doi.org/10.1016/0304-422X(92)90008-Q

Prieto-Rodríguez, J., \& Fernández-Blanco, V. (2000). Are Popular and Classical Music Listeners the Same People? Journal of Cultural Economics, 24(2), 147-164. https://doi.org/10.1023/A:1007620605785

Rallet, A., \& Rochelandet, F. (2007). ICTs and Inequalities: The Digital Divide. In Brousseau E. and Curien N. (eds), Internet and Digital Economics. Cambridge University Press. https://doi.org/10.1017/CBO9780511493201.025

Relish, M. (1997). It's Not all Education: Network Measures as Sources of Cultural Competency. Poetics, 25, 121-139. https://doi.org/10.1016/S0304-422X(97)00011-9

Rochelandet, F., \& Le Guel, F. (2005). P2P Music-Sharing Networks: Why legal Fight Against Copiers May Be Inefficient. Review of Economic Research on Copyright Issues, 2(2), 69-82. https://doi.org/10.2139/ssrn.810124

Sciadas G. (2002). Unveiling the Digital Divide, Statistics Canada: Science, Innovation and Electronic Information Division. Retrieved from http://www.statcan.ca

Seaman, B. A. (2006). Empirical Studies of Demand for the Performing Arts. In Ginsburgh, V. A., \& Throsby, D., (eds.), Handbook of the Economics of Art and Culture (pp. 415-472). Elsevier. https://doi.org/10.1016/S1574-0676(06)01014-3

Sen, A. (1999). Development as Freedom. Oxford, Oxford University Press.

Seror, A. T., \& Rejeb, S. (1996). Case study of transfer of new technologies: the regional Institute of computer science and telecommunications of Tunis. Publication of the University of Laval.

Throsby, D., \& Withers, G. A. (1979). The Economics of the Performing Arts. Edward Arnold Publishers.

Van Eijck K. (2001). Social Differentiation in Musical Taste Patterns. Social Forces, 79(3), 1163-1184. https://doi.org/10.1353/sof.2001.0017

Well Fadhel, A. (1992). Sequential dynamics: culture-Management. Theoretical foundations and empirical analysis of the Tunisian case, State Thesis in Management Sciences, University of Nice.

World Values Survey. http://www.worldvaluessurvey.org/wvs.jsp, accessed in April 25, 2020 
Zayzafoon, L. (2005). The production of the Muslim woman: Negotiating text, history, and ideology. Lanham, Md.: Lexington Books. 